\title{
Comparison of ultrasound with hysteroscopic and histological findings for intrauterine assessment
}

\author{
Lukas Reznak, Milan Kudela ${ }^{\mathrm{b}, \mathrm{c}}$
}

\begin{abstract}
Introduction. Hysteroscopy with biopsy is a common diagnostic and therapeutic method in gynaecology. Its use is preceded by ultrasound examination. The success rate of predicting intrauterine findings based on ultrasound has not been assessed in the Czech Republic for a long time. In the meantime, there have been technological improvements in ultrasound devices.

Method. Patients indicated for hysteroscopy underwent ultrasound examination and their medical history was recorded. The percentage agreement between ultrasound and histopathological findings was assessed. The secondary goal was to find an easier way of describing ultrasound findings in gynaecological practice.

Results. The study comprised 255 patients. In 15 cases, endometrial carcinoma was confirmed by hysteroscopy and histopathological examination. Of these, malignancies were suspected based on previous ultrasound scans in 11 patients. In 95 cases, intrauterine polyps were detected. The success rate for predicting polyps by ultrasound examination was $65.1 \%$. The agreement between ultrasound and hysteroscopic/histopathological findings was $72 \%$. The secondary goal of making the description of the uterine cavity easier was not fulfilled. The prediction percentages for the criteria were low. The incidence of pathological findings in ultrasound findings labelled as anechogenic was $4.8 \%$, suggesting a high negative predictive value.

Conclusion. In spite of the better resolution of new ultrasound devices, their predictive value remains limited. Findings that are suspicious in ultrasound should be confirmed by hysteroscopy with biopsy.
\end{abstract}

Key words: hysteroscopy, ultrasound, histology, comparison

Received: August 20, 2017; Accepted: March 19, 2018; Available online: March 27, 2018 https://doi.org/10.5507/bp.2018.010

${ }^{a}$ Department of Gynaecology and Obstetrics, Vitkovicka Nemocnice Hospital, Ostrava, Czech Republic ${ }^{b}$ Department of Gynaecology and Obstetrics, University Hospital, Olomouc, Czech Republic 'Department of Health Care Sciences, Faculty of Humanities, Tomas Bata University, Zlin, Czech Republic Corresponding author: Lukas Reznak, e-mail:Reznak2@seznam.cz

\section{INTRODUCTION}

Ultrasound is a common part of gynaecological examination. With improving technological aspects of this procedure, there should be an increasing ability to predict pathological findings using this diagnostic method. The main goal of this study was to assess the success rate of ultrasound findings in comparison to hysteroscopy with biopsy. The data were collected from January to December 2015 and, following grant support from Palacký University, from March to December 2016. The secondary goal was to find an easier way to describe the uterine cavity for prediction of pathological findings, especially malignant lesions and polyps. The reason was a lack of consistency in describing ultrasound images. The results were presented as percentage agreement between predefined ultrasound images and hysteroscopy.

\section{METHOD}

The patients, referred by their gynaecologist for suspicious findings in the uterine cavity, were examined and their details recorded age, menopausal status and/or bleeding irregularities. The ultrasound images were de- scribed in the anteroposterior plane, endometrial thickness was measured and regularity of the junctional zone was evaluated; when indicated, colour Doppler was used. Ultrasound was used to assess the major finding to be further evaluated. All images were assessed by one person (the author) using the GE Voluson E8.

In an effort to make descriptions of the uterine cavity easier, we proposed the following 4 sonographic features: (a) homogeneous echogenicity (the same shade of grey throughout the uterine cavity); (b) mixed echogenicity (varying shades of grey); (c) anechogenic (dark grey throughout the cavity); and (d) hyperechogenic lesion with an anechogenic border.

In case of suspicious or uncertain ultrasound findings, the lesion was measured and colour Doppler could be used. Hysteroscopic examination included description of the uterine cavity, especially the appearance and thickness of the endometrium. During hysteroscopy, the endometrium was assessed by a surgeon. If a pathological lesion was revealed by hysteroscopy, its appearance was evaluated, especially vascularity and presence of necrosis, and its size and location were estimated. If suspicious, a biopsy was taken. Polyps were removed. If hysteroscopy showed no pathology, simple smears of the cervix and uterine cavity were taken. 
Table 1. Age distribution.

\begin{tabular}{ccccccc}
\hline Age & $20-29$ & $30-39$ & $40-49$ & $50-59$ & $60-69$ & $70+$ \\
\hline $\mathrm{n}=255$ & $3(1.2 \%)$ & $12(4.7 \%)$ & $35(13.7 \%)$ & $66(25.9 \%)$ & $90(35.3 \%)$ & $49(19.2 \%)$ \\
\hline
\end{tabular}

Table 2. Symptoms and menopause status.

\begin{tabular}{lcc}
\hline & Premenopausal patients & Postmenopausal patients \\
\hline Symptomatic patients & 33 & 38 \\
Asymptomatic patients & 25 & 159 \\
\hline
\end{tabular}

Table 3. Symptomatic patients.

\begin{tabular}{lcc}
\hline & Polyps and endometrial carcinoma & Negative results \\
\hline $\mathrm{n}=71$ & 28 & 43 \\
\hline
\end{tabular}

Table 4. Endometrial thickness.

\begin{tabular}{lccc}
\hline Endometrial thickness & $\leq 7 \mathrm{~mm}$ & $8-15 \mathrm{~mm}$ & $\geq 16 \mathrm{~mm}$ \\
\hline $\mathrm{n}=255$ & 150 & 87 & 18 \\
\hline
\end{tabular}

Table 5. Histopathological results.

\begin{tabular}{cccccc}
\hline $\begin{array}{c}\text { Atrophic } \\
\text { endometrium }\end{array}$ & $\begin{array}{c}\text { Hyperproliferative endometrium (simplex, } \\
\text { complex and atypical hyperplasia) }\end{array}$ & $\begin{array}{c}\text { Endometrial } \\
\text { carcinoma }\end{array}$ & Polyps & $\begin{array}{c}\text { Other results (e.g. } \\
\text { dysfunctional endometrium) }\end{array}$ \\
\hline $\mathrm{n}=255$ & $101(39.6 \%)$ & $36(14.1 \%)$ & $15(6.0 \%)$ & $83(32.5 \%)$ & $20(7.8 \%)$ \\
\hline
\end{tabular}

Table 6. Percentage correlations between ultrasound-predicted pathologies and histopathological results.

\begin{tabular}{lcccc}
\hline & $\begin{array}{c}\text { Homogeneous } \\
\text { echogenicity }\end{array}$ & $\begin{array}{c}\text { Mixed } \\
\text { echogenicity }\end{array}$ & $\begin{array}{c}\text { Anechogenic } \\
\text { Hyperechogenic lesions } \\
\text { with anechoic borders }\end{array}$ \\
\hline correlations & $55.2 \%$ & $58.3 \%$ & $4.80 \%$ & $67.30 \%$ \\
\hline
\end{tabular}

All the data were evaluated as a whole and then split into groups. The patients were classified as asymptomatic/ symptomatic and pre-/postmenopausal.

Since most malignancies appear as polyps in later stages, the ability to assess the polyps was evaluated. Four groups made for easier ultrasound description were evaluated as positive or negative. Hysteroscopically confirmed polyps and histologically confirmed carcinoma were considered positive. The rest of the patients were classified as negative.

\section{RESULTS}

A total of 255 ultrasound examinations and the same number of hysteroscopic procedures were performed. The patients' ages ranged from 20 to 85 . The age distribution is shown in Table 1.

There were 197 postmenopausal and 58 premenopausal patients. The relationships between menopause status and symptoms in the form of bleeding are shown in Table 2.

Endometrial carcinoma was histologically confirmed in one premenopausal woman suffering from irregular bleeding. A total of $72.7 \%$ of premenopausal women were diagnosed with proliferative, secretory or atrophic endometrium. There were three cases of confirmed polyps, one case of atypical hyperplasia among asymptomatic premenopausal patients and two cases of confirmed atypical hyperplasia among asymptomatic postmenopausal women. Atypical hyperplasia was never found insymptomatic women.

Seventy-one patients were classified as symptomatic. The relationships between symptoms and confirmed findings are shown in Table 3.

There were seven patients with confirmed endometrial carcinoma and 21 individuals with benign polyps in the group of patients with irregular bleeding. The frequency of these findings in symptomatic patients was $39.4 \%$, with carcinoma being present in $9.9 \%$ of the patients.

Based on endometrial thickness measurements, the entire sample was divided into three subgroups as seen in Table 4.

In patients with endometrial thickness of $16 \mathrm{~mm}$ or more, endometrial carcinoma was confirmed in 7 cases (38.9\%) and polyps in 3 cases.

The junctional zone was interrupted in 27 individuals, of whom 7 (25.9\%) were diagnosed with malignancies. 
The distribution of histopathological results can be seen in Table 5.

All 15 malignant findings were confirmed as endometrial carcinoma. One was found in a premenopausal patient. Of these, eight patients (53.3\%) were asymptomatic. Ultrasound failed to identify 4 cases as malignant. The mean endometrial thickness in patients suffering from carcinoma was $15.6 \mathrm{~mm}$ (range, 7-25 $\mathrm{mm}$ ). Their mean age was 67 years. The malignant lesions appeared hyperechoic on ultrasound. The junctional zone was not always intact, being interrupted in half of the cases. In none of the patients was fluid present in the peritoneal cavity. No increased vascularity was detected by colour Doppler. There is no evidence of ultrasound signs that can distinguish atypical hyperplasia between other forms of hyperplasia. Hyperproliferative endometrium in this case combines simplex, complex and atypical hyperplasia.

The percentage correlations between ultrasound prediction based on the simplified version of description and histopathological results are shown in Table 6.

Anechogenic findings in the uterine cavity are connected with a higher negative predictive value. The data clearly show that the simplified ultrasound description does not make the diagnosis of uterine cavity lesions easier. It is neither reliable nor useful for common practice.

Ultrasound scans found polyps in 146 cases of which 95 were confirmed by hysteroscopy. When polyps found by hysteroscopy but not by previous ultrasound examination were included, the success rate of predicting polyps was $53.4 \%$.

The absolute success rate of predicting any lesions in the uterine cavity using ultrasound was $72 \%$.

\section{DISCUSSION}

Hysteroscopy is the most frequent method for diagnosing the cause of uterine bleeding. The most feared cause is endometrial carcinoma. In the Czech Republic, a total of 1934 new cases of endometrial carcinoma were diagnosed in 2014. In the same year, 433 patients died of the condition ${ }^{1}$.

According to many studies, an endometrial thickness of $10 \mathrm{~mm}$ is the cut-off for performing hysteroscopy. However, the incidence of this type of carcinoma in postmenopausal asymptomatic patients is less than $0.002 \%$. Despite high ultrasound sensitivity, there is $34 \%$ chance of finding low thickness of the endometrium in non-oestrogen dependent carcinomas ${ }^{2}$.

The potential risk of malignant endometrial polyps is $0-4.8 \%$ (ref. $^{2}$ ). The risk is increased by postmenopause, higher age, hypertension, large polyps and the use of tamoxifen $^{3,4}$. The prevalence of malignant tumours and hyperplasia of the endometrium is $3.2 \%$ in symptomatic and $3.9 \%$ in asymptomatic women ${ }^{5}$. According to one Czech study, intrauterine carcinomas were more reliably predicted by hysteroscopy than by sonography in patients with $5 \mathrm{~mm}$ thickness of the endometrium ${ }^{6}$. There is poor accuracy of endometrial thickness measured with trans- vaginal ultrasound for assessing carcinoma. A routine use of endometrial thickness measurements with transvaginal ultrasound does not seem to be an effective tool for diagnosing endometrial cancer because it has low diagnostic performance in asymptomatic postmenopausal women ${ }^{7}$.

The prevalence of endometrial polyps is $7.8-34.9 \%$ based on the definition of polyps, diagnostic method used and the type of population studied. The prevalence rises with age; however, they may also be found accidentally ${ }^{2}$. Among women undergoing diagnostic hysteroscopy and blind polypectomy, polyps were more common in the age group of 40-49 years. Polyps manifested as abnormal uterine bleeding in $45.6 \%$ (ref. $^{8}$ ). There is no relation between symptoms and the size or number of polyps ${ }^{9}$. The presence of polyps also may not be the cause of uterine bleeding. Polyps were confirmed in up to $28 \%$ of symptomatic postmenopausal women ${ }^{2}$. In 134 patients who underwent hysteroscopy, the procedure revealed a diagnostic accuracy higher than $90 \%$ for all the diseases evaluated, while transvaginal ultrasonography showed an accuracy of $65.9 \%$ for polyps ${ }^{10}$. Higher sensitivty up to $89 \%$ and specificity up to $87 \%$ is obtained when using color-flow sonography and detecting one feeding blood vesse $^{11}$. In the most recent study, there was a $62 \%$ positive predictive value and $99 \%$ negative predictive value for detection of endometrial polyps. This study comprised 789 premenopausal women and had $94 \%$ sensitivity and $95 \%$ specificity of hysteroscopical procedure, while transvaginal ultrasound had sensitivity $54 \%$ and specificity $80 \%$ for detection endometrial polyps ${ }^{12}$. Ideally, after initial investigation with transvaginal ultrasonography, guided biopsy of the lesion should be performed by hysteroscopy, whenever necessary, in order to improve the diagnostic accuracy and subsequent clinical management ${ }^{10}$.

There is a chance for spontaneous regression of polyps, higher for smaller ones ${ }^{13}$. In a period of $37.57 \pm 28.12$ months, $3.9 \%$ had recurrence. In a follow-up period of $16.56 \pm 18.96$ months, $78.9 \%$ women did not have any recurrence $^{8}$.

According to a Turkish study aimed at sonographic description of the endometrium, there is significant correlation between ultrasound findings and histopathological results. Homogeneous thickening was detected in $13.4 \%$ of patients, of whom approximately $51 \%$ had proliferative endometrium. Cystic thickening was detected in $6.0 \%$ of patients of whom nearly $57 \%$ had proliferative endometrium. The sonographic success rate of predicting polyps was $44.7 \%$ (ref. $^{14}$ ).

\section{CONCLUSION}

Prediction of uterine masses using ultrasound as the only diagnostic method is rather difficult. These days, endometrial carcinoma is detected in its early stages, as a result of early symptoms (bleeding) and preventive ultrasound examination performed in asymptomatic patients. Ultrasound examination is not reliable for assessing intrauterine masses. Suspicious ultrasound findings need 
to be followed by hysteroscopy with targeted biopsy and histopathological examination.

\section{REFERENCES}

1. Národní onkologický registr za rok 2014. NZIS Report č. R/1 (09/2016). (In Czech)

2. Kužel D, Toth D, Mára M. Základy panoramatické hysteroskopie. Grada Publishing 2016 (In Czech)

3. Ben-Arie A, Goldchmit C, Laviv Y, Levy R, Caspi B, Huszar M, Dqani $R$, Haqay Z. The malignant potential of endometrial polyps. EUR J Obstet Gynecol Reprod Biol 2004; 115: 206-210

4. Cohen I. Endometrial pathologies associated with postmenopausal tamoxifen treatment. Gynecol Oncol 2004;94:256-66

5. Lieng M, Qvigstad E, Sandvik L, Jorgensen H, Langerbrekke A, Istre O. Hysteroscopic resection of symptomatic and asymptomatic endometrial polyps. J Minim Invasive Gynecol 2007; 14: 189-194

6. Kudela M., Pilka R., Hejtmánek P., Dzvinčuk P., Ondrová D. Význam sonografie a hysteroskopie u suspektních nálezů na endometriu menopauzálních žen. Čes Gynek 2008;73(2):104-8. (In Czech)

7. Yasa C, Dural O, Bastu E, Ugurlucan FG, Nehir A, liyibozkurt AC. Evaluation of the diagnostic role of transvaginal ultrasound measurements of endometrialthickness to detect endometrial malignancy in asymptomatic postmenopausal women. Arch Gynecol Obstet 2016;294(2):311-6.
8. Kanthi JM, Remadevi C, Sumathy S, Sharma D, Sreedhar S, Jose A. Clinical Study of Endometrial Polyp and Role of Diagnostic Hysteroscopy and Blind Avulsion of Polyp. J Clin Diagn Res 2016;10(6):QC01-4

9. Hassa H, Telkin B, Senses T, Kaya M, Karatas A. Are the site, diameter and number of endometrial polyps related with symptomatology? Am J Obstet Gynecol 2006;194:718-21.

10. Wanderley MD, Álvares MM, Vogt MF, Sazaki LM. Accuracy of Transvaginal Ultrasonography, Hysteroscopy and Uterine Curettage in Evaluating Endometrial Pathologies. Rev Bras Ginecol Obstet 2016;38(10):506-11.

11. Alcázar JL, Castillo G, Mínguez JA, Galán MJ. Endometrial blood flow mapping using transvaginal power Doppler sonography in women with postmenopausal bleeding and thickened endometrium. Ultrasound Obstet Gynecol 2003;21(6):583-8.

12. Shiva M, Ahmadi F, Arabipoor A, Oromiehchi M, Chehrazi M. Accuracy of Two-Dimensional Transvaginal Sonography and Office Hysteroscopy for Detection of Uterine Abnormalities in Patients with Repeated Implantation Failures or Recurrent Pregnancy Loss. Int J Fertil Steril 2018;11(4):287-92.

13. Lieng M, Istre O, Sandvik L, Qvigstad E. Prevalence, 1- year Regression Rate and Clinical Significance of Asymptomatic Endoetrial Polyps: Cross-sectional study. J Minim Invasive Gynecol 2009;16:465-71.

14. Ozer A, Ozer S, Kanat-Pektas M. Correlation between transvaginal ultrasound measured endometrial thickness and histopathological findings in Turkish women with abnormal uterine bleeding. J Obstet Gynaecol Res 2016;42(5):573-8. 